Check for updates

Cite this: RSC Adv., 2017, 7, 53032

\title{
Interacting layered hydroxide nanosheets with KF leading to Y/Eu hydroxyfluoride, oxyfluoride, and complex fluoride nanocrystals and investigation of photoluminescence $\uparrow$
}

\author{
Jing Li, ${ }^{\text {ab }}$ Xuejiao Wang, (DD *c Qi Zhu, ${ }^{\text {ab }}$ Byung-Nam Kim, ${ }^{\text {d }}$ Xudong Sun ${ }^{\text {abe }}$ \\ and Ji-Guang $\mathrm{Li}$ (iD)*abd
}

Treating nanosheets ( $4 \mathrm{~nm}$ thick) of $\mathrm{RE}_{2}(\mathrm{OH})_{5} \mathrm{NO}_{3} \cdot \mathrm{nH}_{2} \mathrm{O}$ layered hydroxyl nitrate (LREH- $\mathrm{NO}_{3}{ }^{-}, \mathrm{RE}=$ $\left.\mathrm{Y}_{0.95} \mathrm{Eu}_{0.05}\right)$ with $\mathrm{KF}$ solution at a low temperature of $\sim 90{ }^{\circ} \mathrm{C}$ yielded $\mathrm{F}^{-}$-substituted LREH $\left(\mathrm{RE}_{2}(\mathrm{OH})_{5} \mathrm{~F} \cdot n \mathrm{H}_{2} \mathrm{O}\right), \mathrm{RE}(\mathrm{OH})_{3-x} \mathrm{~F}_{x}$ hydroxyfluoride $(x=1.15-1.51)$, and $\mathrm{K}_{5} \mathrm{RE}_{9} \mathrm{~F}_{32}$ complex fluoride depending on the F/RE molar ratio $(R)$ used for phase conversion $(R=3: 3-200: 3)$. Calcining $R E(O H)_{3-x} F_{x}$ of a relatively high $\mathrm{F}$ content $(x=1.29-1.51, R=40: 3-70: 3)$ at $450{ }^{\circ} \mathrm{C}$ in air produced $\mathrm{REO}_{(3-x) / 2} \mathrm{~F}_{x}$ oxyfluorides, with the F/RE molar ratio close to that of the orthorhombic structured $\mathrm{Y}_{5} \mathrm{O}_{4} \mathrm{~F}_{7}$ phase. Oxidation of $\mathrm{REO}_{(3-x) / 2} \mathrm{~F}_{x}$ to form REOF and even $\mathrm{RE}_{2} \mathrm{O}_{3}$ was observed at temperatures above $\sim 700{ }^{\circ} \mathrm{C}$. The materials were characterized in depth by the combined techniques of elemental analysis, XRD, FE-SEM, TEM, FTIR, and TG to reveal the process of composition, phase, and morphology evolution, and the photoluminescent properties of the resultant hydroxyfluoride, oxyfluoride and complex fluoride were also elaborated with regard to the crystal structure of the host lattice, F content, and the temperature of

calcination.

Received 22nd September 2017 Accepted 10th November 2017

DOI: $10.1039 / \mathrm{c} 7 \mathrm{ra10508h}$

rsc.li/rsc-advances

\section{Introduction}

Rare-earth fluorides normally possess a high refractive index $(\sim 1.56)$, a low phonon energy $\left(\sim 350-500 \mathrm{~cm}^{-1}\right)$, and adequate thermal and environmental stability, and therefore are regarded as excellent host lattices for down- and up-conversion luminescence of lanthanide ( $\mathrm{Ln}$ ) ions. ${ }^{\mathbf{1 - 1 5}}$ Among the investigated fluorides, the $\mathrm{Y}(\mathrm{OH})_{3-x} \mathrm{~F}_{x}$ hydroxyfluoride and $\mathrm{YO}_{(3-x) / 2} \mathrm{~F}_{x}$ oxyfluoride have been drawing great attention due to their significantly broader anion miscibility than their chloride and bromide counterparts of fixed anion substitution phases. ${ }^{16}$ It was also reported that $\mathrm{Y}(\mathrm{OH})_{3-x} \mathrm{~F}_{x}$ would decompose to $\mathrm{YO}_{(3-x) / 2} \mathrm{~F}_{x}$ and a mixture of $\mathrm{Y}_{2} \mathrm{O}_{3}$ and YOF when $x \geq 1$ and $x<1$,

${ }^{a}$ Key Laboratory for Anisotropy and Texture of Materials (Ministry of Education), Northeastern University, Shenyang, Liaoning 110819, China

${ }^{b}$ Institute of Ceramics and Powder Metallurgy, School of Materials Science and Engineering, Northeastern University, Shenyang, Liaoning 110819, China

'College of New Energy, Bohai University, Jinzhou, Liaoning 121000, China. E-mail: wangxuejiao@bhu.edu.cn; Tel: +86-416-3400708

${ }^{d}$ Research Center for Functional Materials, National Institute for Materials Science, 1-1 Namiki, Tsukuba, Ibaraki 305-0044, Japan. E-mail: LI.Jiguang@nims.go.jp; Tel: +8129-860-4394

'Liaoning Engineering Laboratory of Special Optical Functional Crystals, College of Environment and Chemical Engineering, Dalian University, Dalian, Liaoning 116622, China

$\dagger$ Electronic supplementary information (ESI) available. See DOI: $10.1039 / \mathrm{c} 7 \mathrm{ra} 10508 \mathrm{~h}$ respectively. ${ }^{14,16}$ Aside from the benefit that the $\mathrm{Y}$ site of $\mathrm{Y}(\mathrm{OH})_{3-x} \mathrm{~F}_{x}$ and $\mathrm{YO}_{(3-x) / 2} \mathrm{~F}_{x}$ can be facilely substituted by an $\mathrm{Ln}^{3+}$ activator without additional charge compensation, the alterable $\mathrm{OH}^{-} / \mathrm{F}^{-}$and $\mathrm{O}^{2-} / \mathrm{F}^{-}$ligand molar ratio of these two types of compounds may offer great opportunities for engineering the local symmetry and crystal field strength to achieve tunable luminescence.

The synthesis of $\mathrm{Y}(\mathrm{OH})_{3-x} \mathrm{~F}_{x}$ with changeable $x$ value was exemplified by hydrothermal reaction under very high temperature and pressure. For example, $\mathrm{Y}(\mathrm{OH})_{3-x} \mathrm{~F}_{x}$ with the lower $\mathrm{F}$ content of $0.65<x<1.43$ is obtainable via hydrothermally reacting $\mathrm{Y}_{2} \mathrm{O}_{3}$ and $\mathrm{KF}$ at $400{ }^{\circ} \mathrm{C}$ and $25 \mathrm{MPa}$ and that with the higher $\mathrm{F}$ content of $1.5<x<2.0$ can be synthesized via reacting $\mathrm{Y}_{2} \mathrm{O}_{3}$ and $\mathrm{HF}$ at $450{ }^{\circ} \mathrm{C}$ and $4 \mathrm{~kb} \cdot{ }^{16,17}$ Recently, $\mathrm{RE}(\mathrm{OH})_{3-x} \mathrm{~F}_{x}$ (RE: rare-earth) with some fixed $x$ values $(0.86,0.98,1.13,1.43$, and 1.90) was obtained via hydrothermal reaction at the lower temperatures of up to $220{ }^{\circ} \mathrm{C}, \mathbf{4 , 6 , 1 4 , 1 8}$ and the nano-/micro-crystals of several types of oxyfluorides $\left(\mathrm{RE}_{7} \mathrm{O}_{6} \mathrm{~F}_{9}, \mathrm{RE}_{6} \mathrm{O}_{5} \mathrm{~F}_{8}, \mathrm{RE}_{5} \mathrm{O}_{4} \mathrm{~F}_{7}\right.$, and REOF) were produced via thermolysis of precipitation products and by solid reaction. ${ }^{\mathbf{8 , 1 9 , 2 0}}$ With these successes, the photoluminescent properties of the hydroxyfluoride and oxyfluoride products were investigated., ${ }^{\mathbf{4 , 6}, 9,11,21-23}$

Controlled synthesis of rare-earth compounds has also been achieved by the phase conversion technique, ${ }^{24-28}$ which generally involves the two different mechanisms of interface chemical transformation ${ }^{25,26}$ and dissolution-reprecipitation. ${ }^{24,27,28}$ 
The former applies when the precursor and target compound have the same crystal structure. In the course of phase conversion, the precursor serves as both a physical and chemical template and as a result the final product can well preserve the crystallite morphology of the precursor. This is evidenced by the hydrothermal conversion of hexagonal structured $\mathrm{RE}(\mathrm{OH})_{3}$ nanorods/nanotubes into hexagonal $\beta-\mathrm{NaREF}_{4}$ crystallites of the same morphology. ${ }^{25,26}$ The dissolution-reprecipitation mechanism takes the role when the precursor and final product differ in crystal structure, as shown by the evolution of $\mathrm{LuBO}_{3}$ microdiscs (hexagonal structured) upon reacting $\mathrm{Lu}_{4}{ }^{-}$ $\mathrm{O}(\mathrm{OH})_{9} \mathrm{NO}_{3}$ nanowires (monoclinic structured) with boric acid $\left(\mathrm{H}_{3} \mathrm{BO}_{3}\right) \cdot{ }^{24} \mathrm{REF}_{3}$ and $\mathrm{Na}_{x} \mathrm{RE}_{y} \mathrm{~F}_{x+3 y}$ hollow spheres have also been hydrothermally converted from amorphous $\mathrm{RE}(\mathrm{OH}) \mathrm{CO}_{3}$ colloidal spheres in the presence of $\mathrm{NaBF}_{4}$ (ref. 27) or $\mathrm{NaF}^{28}$

We employed in this work the phase conversion strategy to synthesize $\mathrm{Eu}^{3+}$ doped $\mathrm{Y}(\mathrm{OH})_{3-x} \mathrm{~F}_{x}$ with the nanosheets of $\mathrm{RE}_{2}(\mathrm{OH})_{5} \mathrm{NO}_{3} \cdot n \mathrm{H}_{2} \mathrm{O}$ layered hydroxyl nitrate $\left(\mathrm{LREH}-\mathrm{NO}_{3}{ }^{-}\right.$) as a new type of sacrificial precursor. The crystal structure of LREH$\mathrm{NO}_{3}{ }^{-}$is constructed via alternative stacking of the $\left[\mathrm{RE}_{2}(\mathrm{OH})_{5}{ }^{-}\right.$ $\left.\left(\mathrm{H}_{2} \mathrm{O}\right)_{n}\right]^{+}$host layer and anion-exchangeable interlayer $\mathrm{NO}_{3}{ }^{-}$ along the $c$-axis ([001] direction). ${ }^{29}$ The compound received much research interest owing to the diverse and unique physicochemical properties of RE, particularly in the areas of nanosheets exfoliation via anion exchange of the parent crystals, assembly of the delaminated nanosheets into multi-functional films, and derivation of luminescent oxide powders and oriented films. ${ }^{29-43}$ Different from the traditional $\mathrm{LREH}^{-\mathrm{NO}_{3}}{ }^{-}$ synthesis via reflux precipitation and hydrothermal reaction, which inevitably yield platelike thick crystals, we developed a "freezing-temperature crystallization" technique that can directly produce $\mathrm{LREH}_{-} \mathrm{NO}_{3}{ }^{-}$nanosheets of only $\sim 4 \mathrm{~nm}$ thick in an acceptable batch quantity. ${ }^{37}$ The technique was conceived

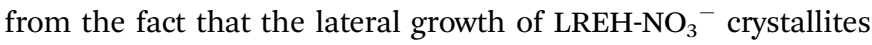
needs lower activation energy than thickness growth because the hydroxide main layers are close-packed crystal planes. As a result, much thinner platelets (nanosheets) can be directly yielded by restricting the thickness growth through lowering the reaction temperature to $\sim 4{ }^{\circ} \mathrm{C}$. Another distinct advantage of this technique is that it is widely applicable to the RE elements of $\mathrm{Pr}-\mathrm{Er}$ in the lanthanide family (excluding radioactive $\mathrm{Pm}$ ) ${ }^{37}$ To the best of our knowledge, however, sacrificial conversion of LREH-NO ${ }_{3}{ }^{-}$into fluoride compounds via reacting with $\mathrm{KF}$ has hardly been reported prior to us. The phase, morphology, and composition evolution during phase conversion and subsequent calcination and also the photoluminescent properties of the resultant fluoride compounds were investigated in detail.

\section{Experimental}

\section{Reactants and materials synthesis}

$\mathrm{Eu}\left(\mathrm{NO}_{3}\right)_{3} \cdot 6 \mathrm{H}_{2} \mathrm{O}(99.95 \%$ pure $)$ and $\mathrm{Y}\left(\mathrm{NO}_{3}\right)_{3} \cdot 6 \mathrm{H}_{2} \mathrm{O}(99.99 \%$ pure $)$ were purchased from Kanto Chemical Co. (Tokyo, Japan) while $\mathrm{NH}_{4} \mathrm{OH}$ solution (25\%) and $\mathrm{KF}$ (99\% pure) were purchased from Wako Pure Chemical Industries, Ltd. (Osaka, Japan).

For the synthesis of $\mathrm{RE}_{2}(\mathrm{OH})_{5} \mathrm{NO}_{3} \cdot n \mathrm{H}_{2} \mathrm{O}$ layered hydroxide nanosheets $\left(\mathrm{RE}=\mathrm{Y}_{0.95} \mathrm{Eu}_{0.05}\right.$, hereafter referred to $\left.\mathrm{LREH}-\mathrm{NO}_{3}{ }^{-}\right)$,
$250 \mathrm{~mL}$ of a $0.2 \mathrm{~mol} \mathrm{~L}^{-1}$ aqueous solution of $\mathrm{RE}\left(\mathrm{NO}_{3}\right)_{3}$ was precooled to $\sim 4{ }^{\circ} \mathrm{C}$ with a cool circulator, followed by dropwise addition of $\mathrm{NH}_{4} \mathrm{OH}$ aqueous solution $\left(1 \mathrm{~mol} \mathrm{~L}^{-1}\right)$ till $\mathrm{pH} \sim 8.0 .^{37}$ After aging for $1 \mathrm{~h}$, the resultant suspension was suction filtrated and the precipitate was washed with deionized water two times and ethanol once, followed by drying in air at $70{ }^{\circ} \mathrm{C}$ for $24 \mathrm{~h}$.

For phase conversion, a certain amount of $\mathrm{KF}$ was dissolved in $50 \mathrm{~mL}$ of deionized water at room temperature, to which $3 \mathrm{mmol}$ of the as-prepared $\mathrm{LREH}-\mathrm{NO}_{3}{ }^{-}$was added. The F/RE molar ratio $(R)$ was varied in the wide range of 0-200 to investigate its effect on product property. After homogenizing under magnetic stirring for $10 \mathrm{~min}$, the suspension was transferred into a capped glass tube for reaction at $90{ }^{\circ} \mathrm{C}$ for $3 \mathrm{~h}$. The resultant precipitate was collected by centrifugation, washed with deionized water three times and ethanol once, followed by drying in air at $70^{\circ} \mathrm{C}$ for $12 \mathrm{~h}$.

$\mathrm{REO}_{(3-x) / 2} \mathrm{~F}_{x}$ oxyfluoride was obtained by thermal decomposition of the as-prepared $\mathrm{RE}(\mathrm{OH})_{3-x} \mathrm{~F}_{x}$ in air at a selected temperature for $2 \mathrm{~h}$, with a heating rate of $5{ }^{\circ} \mathrm{C} \min ^{-1}$ at the ramp stage.

\section{Characterization techniques}

Phase identification was performed by powder X-ray diffractometry (XRD, Model RINF 2200 V/PC, Rigaku, Tokyo, Japan) under $40 \mathrm{kV} / 40 \mathrm{~mA}$, using nickel-filtered $\mathrm{Cu}-\mathrm{K} \alpha$ radiation and a scanning speed of $1^{\circ} 2 \theta$ per minute. Phase constituent of the product was analysed via Rietveld fitting of the XRD pattern with the TOPAS software. Product morphology was inspected via field-emission scanning electron microscopy (FE-SEM, Model S-5000, Hitachi, Tokyo) under an acceleration voltage of $10 \mathrm{kV}$ and transmission electron microscopy (TEM, model FEM-3000F, JEOL Ltd., Tokyo) under $300 \mathrm{kV}$. Topographic images of the $\mathrm{LREH}-\mathrm{NO}_{3}{ }^{-}$nanosheets were acquired via atomic force microscopy (AFM, Model NanoScope IIIa, Veeco Instruments Inc., NY) in the tapping mode at the scanning rate of $1 \mathrm{~Hz}$. Fourier transform infrared spectroscopy (FTIR, Model FT/IR-4200, JASCO Co. Ltd., Tokyo) was performed by the standard $\mathrm{KBr}$ pellet method. Thermogravimetry (TG, Model Thermo Plus TG8120, Rigaku) of the dried $\mathrm{RE}(\mathrm{OH})_{3-x} \mathrm{~F}_{x}$ was made in stagnant air with a heating rate of $10{ }^{\circ} \mathrm{C} \min ^{-1}$. Elemental contents of the product were determined for $\mathrm{RE}$ and $\mathrm{K}$ via inductively coupled plasma atomic emission spectroscopy (ICPOES, Model SPS3520UV-DD, SII Nanotechnology, Kyoto, Japan) and for F via the "lanthanum/alizarin complexone (LAC)" absorptiometry technique (Model SPS3520UV-DD, SII Technologies); photoluminescence properties of the products were measured at room temperature using an FP-6500 fluorospectrophotometer, with a $150 \mathrm{~W}$ Xe lamp (JASCO) for excitation and with slit width of $5 \mathrm{~nm}$ for both excitation and emission.

\section{Results and discussion}

\section{Phase/morphology evolution and characterization of the conversion products}

Fig. 1 shows powder XRD patterns of all the products obtained in this work. The precursor precipitated at $\sim 4{ }^{\circ} \mathrm{C}$ exhibits a series of $00 l$ and non- $00 l$ diffractions that are characteristic of 
the orthorhombic structured $\mathrm{LREH}-\mathrm{NO}_{3}{ }^{-}$compound, ${ }^{\mathbf{3 8 , 3 9 , 4 1 , 4 4 , 4 5}}$ whose lattice parameters were analysed to be $a \sim 1.2699(3), b \sim$ $0.7140(1)$, and $c \sim 1.6870(1) \mathrm{nm}$ with the JADE 6.5 software. Reacting the $\mathrm{LREH}-\mathrm{NO}_{3}{ }^{-}$precursor with $\mathrm{KF}$ under the $\mathrm{F} / \mathrm{RE}$ molar ratio of $R=3: 3$ yielded a product that can be assigned to the $\mathrm{F}^{-}$substituted LREH of $\mathrm{RE}_{2}(\mathrm{OH})_{5} \mathrm{~F} \cdot n \mathrm{H}_{2} \mathrm{O}\left(\mathrm{LREH}-\mathrm{F}^{-}\right){ }^{37,46}$ Owing to the electrostatic attraction arising from strong hydrogen bonding between the interlayer $\mathrm{F}^{-}$and the hydroxyls/ $\mathrm{H}_{2} \mathrm{O}$ in the adjacent hydroxide main layers, the interlayer distance $(c / 2)$ of the $\mathrm{LREH}$, calculated from the centre of the 002 peak, contracted from the $\sim 0.844 \mathrm{~nm}$ of $\mathrm{LREH}_{-} \mathrm{NO}_{3}{ }^{-}$to the $\sim 0.740 \mathrm{~nm}$ of LREH-F ${ }^{-}$. Fluorination did not substantially alter the positions of the non-00l diffractions (such as 220), suggesting that the $\left[\mathrm{RE}_{2}(\mathrm{OH})_{5}\left(\mathrm{H}_{2} \mathrm{O}\right)_{n}\right]^{+}$host layers largely remain intact since the non-00 $l$ diffractions come from the $a b$ planes (hydroxide layers). The $R=10: 3$ product shows diffractions that can be well indexed with hexagonal structured $\mathrm{Y}(\mathrm{OH})_{1.57} \mathrm{~F}_{1.43}$ (JCPDS no. 80-2008), though a trace amount of unreacted LREH-F ${ }^{-}$was left behind (indicated with asterisk). ${ }^{37,46}$ The results thus suggest that, at $R=10: 3$, the $\mathrm{F}^{-}$ anions have replaced the water molecules and also a major portion of the hydroxyls in the hydroxide host layers of LREH$\mathrm{F}^{-}$. The products obtained with the larger $R$ values of $20: 3-$ $70: 3$ are hexagonal structured $\mathrm{RE}(\mathrm{OH})_{3-x} \mathrm{~F}_{x}$ of high phase purity, which was proposed to form via the reaction of $\mathrm{RE}_{2}(\mathrm{OH})_{5} \mathrm{~F} \cdot n \mathrm{H}_{2} \mathrm{O}+(2 x-1) \mathrm{KF} \rightarrow 2 \mathrm{RE}(\mathrm{OH})_{3-x} \mathrm{~F}_{x}+(2 x-1) \mathrm{KOH}$ $+n \mathrm{H}_{2} \mathrm{O}$. The results of elemental analysis for the $R=20: 3-$ $70: 3$ products are tabulated in Table 1 , where it is clearly seen that the prescribed Eu content (5 at\%) was well kept to the reaction product in each case and that the F content (the $x$ value in $\left.\mathrm{RE}(\mathrm{OH})_{3-x} \mathrm{~F}_{x}\right)$ gradually increased from $\sim 1.15$ to 1.51 with increasing $R$. It is also notable that the product contains a negligible amount of $\mathrm{K}^{+}$in each case.

Fig. 2 illustrates the lattice constants as a function of the $\mathrm{F}$ content for $\mathrm{RE}(\mathrm{OH})_{3-x} \mathrm{~F}_{x}$. It is seen that the $a$ parameter gradually decreases with increasing $\mathrm{F}$ incorporation while the c parameter keeps almost constant at $\sim 3.55 \AA$. The crystal structure of $\mathrm{RE}(\mathrm{OH})_{3-x} \mathrm{~F}_{x}$ is constructed through linking of each $\mathrm{RE}(\mathrm{O} / \mathrm{F})_{9}$ polyhedron with three adjacent ones by edge-sharing along the $a$ - and $b$-axis and with the other two by face-sharing along the $c$-axis, ${ }^{\mathbf{6}, 16}$ leaving a hexagonal tunnel running along the [001] direction (Fig. S1 $\dagger$ ). As the $a$ constant is related to the

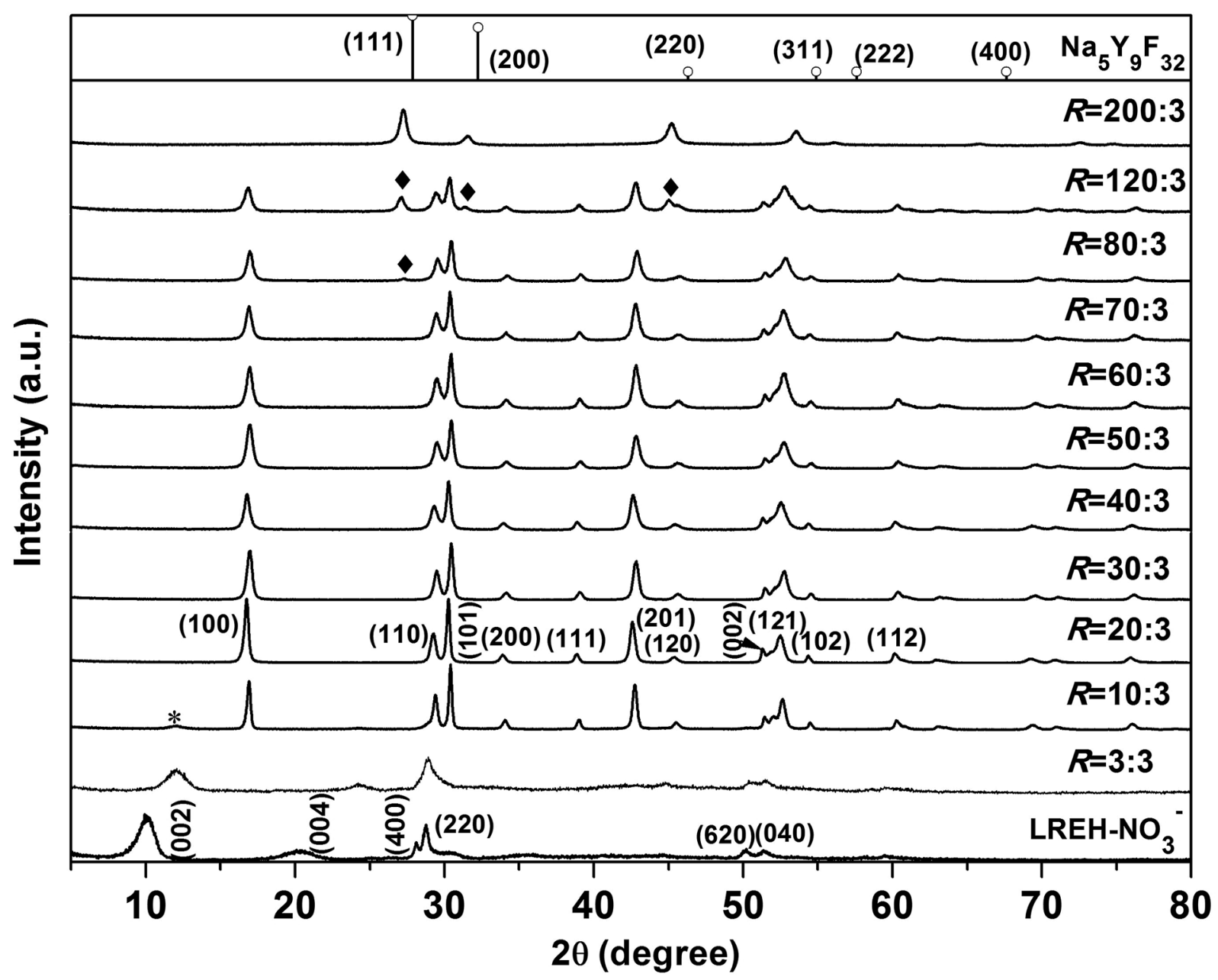

Fig. 1 Powder XRD patterns of the $\mathrm{LREH}-\mathrm{NO}_{3}{ }^{-}$nanosheets and the fluorination products obtained under the different $\mathrm{F} / \mathrm{RE}$ molar ratios $(R)$ indicated in the figure. The standard diffractions of cubic structured $\mathrm{Na}_{5} \mathrm{Y}_{9} \mathrm{~F}_{32}$ (JCPDS no. 27-1428) are included as bars for comparison. 
Table 1 The results of elemental analysis and derived chemical formulae for the phase conversion products

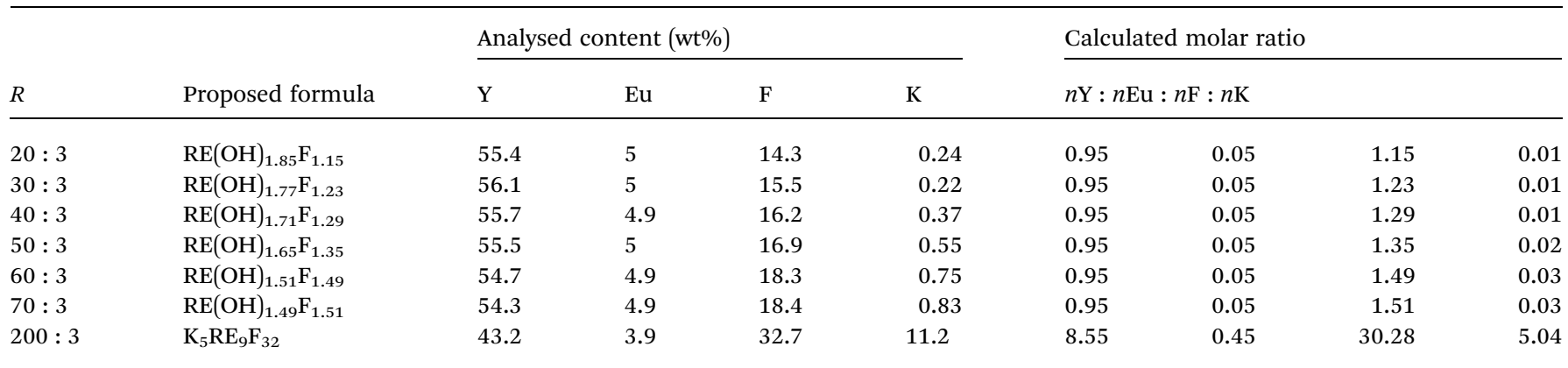

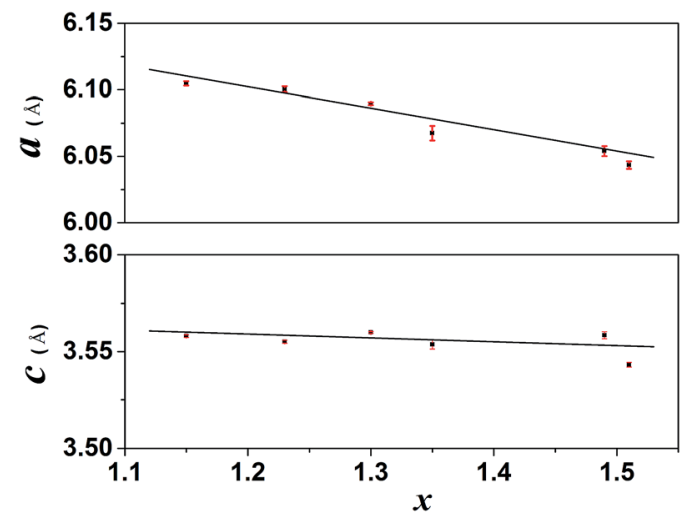

Fig. 2 Correlation of lattice parameters with the F content ( $x$ value, Table 1) for the $\mathrm{RE}(\mathrm{OH})_{3-x} \mathrm{~F}_{x}$ products obtained under the $R$ values of $20: 3-70: 3$

metal-to-metal distance in the $a b$ plane, the increasing hydrogen bonding $\left(-\mathrm{O}-\mathrm{H}^{\cdots} \mathrm{F}-\right)$ with increasing $\mathrm{F}^{-}$content may thus contribute to plane contraction, that is, decreasing $a$ parameter. On the other hand, the main layers ( $a b$ planes) are perpendicular to the $c$ direction and the sizes of $\mathrm{OH}^{-}$and $\mathrm{F}^{-}$are similar $\left(r_{\mathrm{OH}}{ }^{-}=0.137\right.$ and $r_{\mathrm{F}}{ }^{-}=0.133 \mathrm{~nm}$ for $\left.\mathrm{CN}=6\right),{ }^{47}$ so the $c$ parameter remains almost constant. Increasing the F/RE molar ratio to $R=200: 3$ led to the crystallization of a mass that can be indexed with cubic structured $\mathrm{Na}_{5} \mathrm{Y}_{9} \mathrm{~F}_{32}$ (Fig. 1; JCPDS no. 271428). Elemental analysis of this product found the $\mathrm{K}: \mathrm{Y}: \mathrm{Eu}: \mathrm{F}$ molar ratio of $\sim 5.04: 8.55: 0.45: 30.2$ (Table $1, \mathrm{Eu} /(\mathrm{Y}+\mathrm{Eu})=$ 0.05 molar ratio), which is quite close to the $\mathrm{Na}_{5} \mathrm{Y}_{9} \mathrm{~F}_{32}$ analogue of $\mathrm{K}_{5}\left(\mathrm{Y}_{8.55} \mathrm{Eu}_{0.45}\right) \mathrm{F}_{32}$. The compound was proposed to form via the reaction of $9 \mathrm{RE}(\mathrm{OH})_{3-x} \mathrm{~F}_{x}+(32-9 x) \mathrm{KF} \rightarrow \mathrm{K}_{5} \mathrm{RE}_{9} \mathrm{~F}_{32}+$ $(27-9 x) \mathrm{KOH}$. Analysis of this complex fluoride with the JADE 6.5 software found the lattice constant of $a \sim 0.5662(7) \mathrm{nm}$, which is larger than that of $\mathrm{Na}_{5} \mathrm{Y}_{9} \mathrm{~F}_{32}$ in the standard diffraction file ( $a=0.553 \mathrm{~nm}$, JCPDS no. 27-1428). The larger cell parameter of $\mathrm{K}_{5} \mathrm{RE}_{9} \mathrm{~F}_{32}$ is primarily owing to the fact that $\mathrm{K}^{+}(0.151 \mathrm{~nm}$ for $\mathrm{CN}=8$; $\mathrm{CN}$ : coordination number $)$ is larger than $\mathrm{Na}^{+}(0.132 \mathrm{~nm}$ for $\mathrm{CN}=8)$ and $\mathrm{Eu}^{3+}(0.1066 \mathrm{~nm}$ for $\mathrm{CN}=8)$ is larger than $\mathrm{Y}^{3+}$ $(0.1019 \mathrm{~nm}$ for $\mathrm{CN}=8) .{ }^{47-49}$ The $R=80: 3$ and $120: 3$ products are clearly a phase mixture of $\mathrm{RE}(\mathrm{OH})_{3-x} \mathrm{~F}_{x}$ and $\mathrm{K}_{5} \mathrm{RE}_{9} \mathrm{~F}_{32}$ (indicated with rhombus), indicating that under these $R$ values the phase conversion is yet incomplete. It should be pointed out that the efforts to produce $\mathrm{KREF}_{4}$ and $\mathrm{REF}_{3}$ were failed, and one main reason is that the amount (concentration) of KF needed to completely replace the hydroxyls in $\mathrm{RE}(\mathrm{OH})_{3-x} \mathrm{~F}_{x}$ is so high that either $\mathrm{KREF}_{4}$ or $\mathrm{REF}_{3}$ becomes thermodynamically unstable than the $\mathrm{K}_{5} \mathrm{RE}_{9} \mathrm{~F}_{32}$ phase under such conditions.

To better understand the process of phase conversion and the characteristics of the conversion products, we performed FTIR analysis and the results are presented in Fig. 3. For the LREH-NO ${ }_{3}{ }^{-}$nanosheets, the sharp absorption band found at $\sim 1384 \mathrm{~cm}^{-1}$ is typical of the $\nu_{3}$ vibration of uncoordinated $\mathrm{NO}_{3}{ }^{-}$ anions,,$^{33,50,51}$ while those at $\sim 3000-3450 \mathrm{~cm}^{-1}$ and $1641 \mathrm{~cm}^{-1}$ can be assigned to the $\mathrm{OH}$ stretching vibrations $\left(\nu_{1}\right.$ and $\left.\nu_{3}\right)$ and $\mathrm{H}-\mathrm{O}-\mathrm{H}$ bending mode $\left(\nu_{2}\right)$ of $\mathrm{H}_{2} \mathrm{O}$ molecules, respectively. ${ }^{52}$ The existence of hydroxyls $\left(\mathrm{OH}^{-}\right)$is evidenced by the absorption in the $\sim 3500-3750 \mathrm{~cm}^{-1}$ region. The results thus well conform to

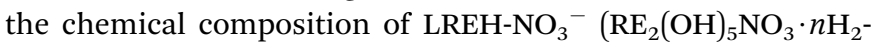

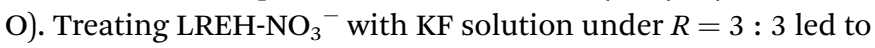
the vanishing of the $\mathrm{NO}_{3}{ }^{-}$absorption but did not appreciably affect the $\mathrm{H}_{2} \mathrm{O}$ and $\mathrm{OH}^{-}$vibrations. Such a result suggests that $\mathrm{F}^{-}$has substituted the interlayer $\mathrm{NO}_{3}{ }^{-}$of $\mathrm{LREH}-\mathrm{NO}_{3}{ }^{-}$to form the LREH-F ${ }^{-}$of $\mathrm{RE}_{2}(\mathrm{OH})_{5} \mathrm{~F} \cdot n \mathrm{H}_{2} \mathrm{O}$. The shallow twin bands in the $\sim 1300-1580 \mathrm{~cm}^{-1}$ region, which partially overlap with the $\mathrm{NO}_{3}{ }^{-}$vibration in the spectrum of $\mathrm{LREH}-\mathrm{NO}_{3}{ }^{-}$, are characteristic of $\mathrm{CO}_{3}{ }^{2-}$ absorptions. The contamination, arising from dissolved atmospheric $\mathrm{CO}_{2}$ and the high affinity of $\mathrm{CO}_{3}{ }^{2-}$ toward $\mathrm{RE}^{3+}$, is common to all the samples synthesized in this work and is also widely observed in $\mathrm{LREH}-\mathrm{NO}_{3}{ }^{-}$studies. The $R$

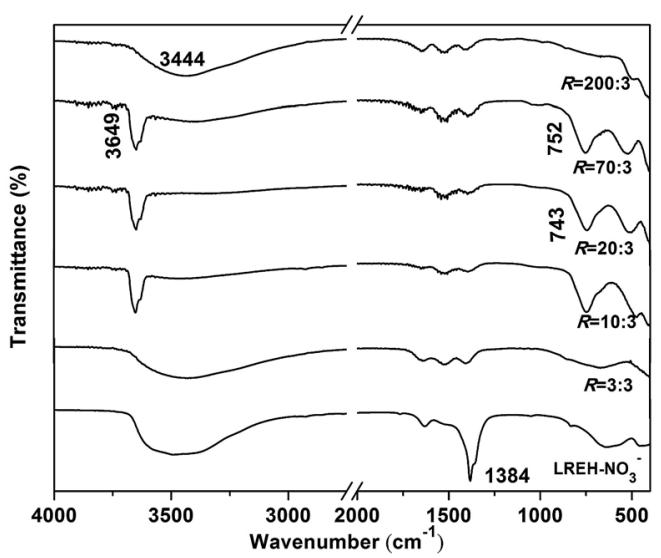

Fig. 3 FTIR spectra for the LREH precursor and typical conversion products obtained under the different $R$ values indicated in the figure. 
$=10: 3-70: 3$ products exhibit FTIR absorptions agreeing with the hydroxyfluoride of $\mathrm{RE}(\mathrm{OH})_{3-x} \mathrm{~F}_{x}$, with the intense and sharp band at $\sim 3649 \mathrm{~cm}^{-1}$, the one in the $\sim 743-752 \mathrm{~cm}^{-1}$ region, and the one at $\sim 500 \mathrm{~cm}^{-1}$ well assignable to the stretching vibrations of virtually free hydroxyls $\left(\mathrm{OH}^{-}\right), \mathrm{OH}^{-}$deformation, ${ }^{52}$ and $v_{t}(\mathrm{RE}-\mathrm{F})$, respectively. The occurrence of $\mathrm{OH}^{-}$deformation vibration also implies the existence of intramolecular $[\mathrm{O}-\mathrm{H} \cdots \mathrm{F}-]$ hydrogen bonding. ${ }^{16}$ The $R=200: 3$ product $\left(\mathrm{K}_{5} \mathrm{RE}_{9} \mathrm{~F}_{32}\right)$ exhibits absorptions arising from $\nu_{t}(\mathrm{RE}-\mathrm{F})$ and $\mathrm{H}_{2} \mathrm{O}$ at the same time, which may indicate that the sample has some adsorbed water molecules. The results of FTIR, XRD, and elemental analysis are well supporting each other, and confirm the proposed pathway of phase evolution.

Fig. 4 exhibits the results of FE-SEM and TEM analysis for some representative reaction products. The LREH- $\mathrm{NO}_{3}{ }^{-}$ precursor $(R=0)$ presents flower-like assembles of nanosheets with the lateral sizes of $\sim 300 \mathrm{~nm}$ and thicknesses of $\sim 4 \mathrm{~nm}$. AFM analysis of the nanosheets (Fig. S2 $\dagger$ ) further confirmed the thickness value determined via TEM observation. The $R=3: 3$ sample (the LREH-F ${ }^{-}$of $\mathrm{RE}_{2}(\mathrm{OH})_{5} \mathrm{~F} \cdot n \mathrm{H}_{2} \mathrm{O}$ ) generally retained the overall morphology of LREH- $\mathrm{NO}_{3}{ }^{-}$as agglomerated nanosheets, but TEM observation found tiny holes on the individual nanosheets arising from KF corrosion. A mixture of prismatic particles (dominant) and some thin-platelets were found for the $R=10: 3$ product, which can be assigned to the newly formed $\mathrm{RE}(\mathrm{OH})_{3-x} \mathrm{~F}_{x}$ and residual LREH-F $^{-}$phases, respectively, according to the results of XRD analysis (Fig. 1). The $R=20: 3$ product exclusively contains dispersed short hexagonal prisms (lengths and diameters up to $\sim 300$ and $100 \mathrm{~nm}$, respectively), in coincidence with the hexagonal crystal structure of $\mathrm{RE}(\mathrm{OH})_{3-x} \mathrm{~F}_{x}$ $(x \sim 1.15$, Table 1$)$ and the single-phase nature of this product. HR-TEM lattice imaging well resolved the (110) crystal plane (interplanar spacing $\sim 0.306 \mathrm{~nm}$ ) and showed that the prisms are elongated along the [001] crystallographic direction. Ricegrain shaped particles of up to $\sim 300 \mathrm{~nm}$ in length were produced by increasing the $R$ value, as shown with the $R=70$ sample for example ( $x \sim 1.51$, Table 1$)$. TEM analysis found that the individual particles are significantly polycrystalline, which is in accordance with the fact that the powder has an average crystallite size of only $\sim 16 \mathrm{~nm}$ as assayed from the XRD pattern with the Scherrer formula. In addition, the interplanar spacing of $\sim 0.303 \mathrm{~nm}$ resolved by HR-TEM is assignable to the (110) plane of $\mathrm{RE}(\mathrm{OH})_{3-x} \mathrm{~F}_{x}$. The as-prepared $\mathrm{K}_{5} \mathrm{RE}_{9} \mathrm{~F}_{32}$ powder $(R=200: 3)$ is composed of nanospheres of up to $\sim 50 \mathrm{~nm}$ in diameter, and the resolved $d$-spacing of $\sim 0.326 \mathrm{~nm}$ may correspond to the (111) crystal plane. The well-resolved lattice fringes also imply good crystallinity of the products, despite of the low phase-conversion temperature of only $\sim 90{ }^{\circ} \mathrm{C}$.

$\mathrm{RE}(\mathrm{OH})_{3-x} \mathrm{~F}_{x}, \mathrm{RE}(\mathrm{OH})_{3}$, and $\beta-\mathrm{NaREF}_{4}$ are all hexagonal structured and present high structure similarities (Fig. $\mathrm{S} 3 \uparrow) .{ }^{5,53,54}$ As in $\mathrm{RE}(\mathrm{OH})_{3}$ and $\beta-\mathrm{NaREF}_{4}$, the $\mathrm{Eu}^{3+}$ activators were proposed to have $C_{3 h}$ symmetry in $\mathrm{RE}(\mathrm{OH})_{3-x} \mathrm{~F}_{x},{ }^{5,53}$ The PL and PLE spectra of $\mathrm{RE}(\mathrm{OH})_{3-x} \mathrm{~F}_{x}$ are shown in Fig. $5(R=20: 3-$ $70: 3, x=1.15-1.51)$. It is seen that the hydroxyfluorides exhibit emissions at $\sim 594 \mathrm{~nm}\left({ }^{5} \mathrm{D}_{0} \rightarrow{ }^{7} \mathrm{~F}_{1}\right.$, medium strong), $618 \mathrm{~nm}$ $\left({ }^{5} \mathrm{D}_{0} \rightarrow{ }^{7} \mathrm{~F}_{2}\right.$, strong), $652 \mathrm{~nm}\left({ }^{5} \mathrm{D}_{0} \rightarrow{ }^{7} \mathrm{~F}_{3}\right.$, weak), and $697 \mathrm{~nm}$ $\left({ }^{5} \mathrm{D}_{0} \rightarrow{ }^{7} \mathrm{~F}_{4}\right.$, medium) under $395 \mathrm{~nm}$ excitation (the ${ }^{7} \mathrm{~F}_{0} \rightarrow{ }^{5} \mathrm{~L}_{6}$ excitation transition of Eu ${ }^{3+}$, Fig. 5). ${ }^{55-58}$ The stronger ${ }^{5} \mathrm{D}_{0} \rightarrow{ }^{7} \mathrm{~F}_{2}$ than ${ }^{5} \mathrm{D}_{0} \rightarrow{ }^{7} \mathrm{~F}_{1}$ transition conforms to the fact that the $\mathrm{Eu}^{3+}$ activators have the relatively low site symmetry of $C_{3 h}$ in $\mathrm{RE}(\mathrm{OH})_{3-x} \mathrm{~F}_{x} \cdot{ }^{59}$ The PLE spectra obtained by monitoring the $618 \mathrm{~nm}$ main emission (Fig. 5, the right-hand inset) similarly consist of a series of sharp lines ascribed to the intra- $4 f^{6}$ transitions of $\mathrm{Eu}^{3+}$ as labelled in the figure. It is seen that both the
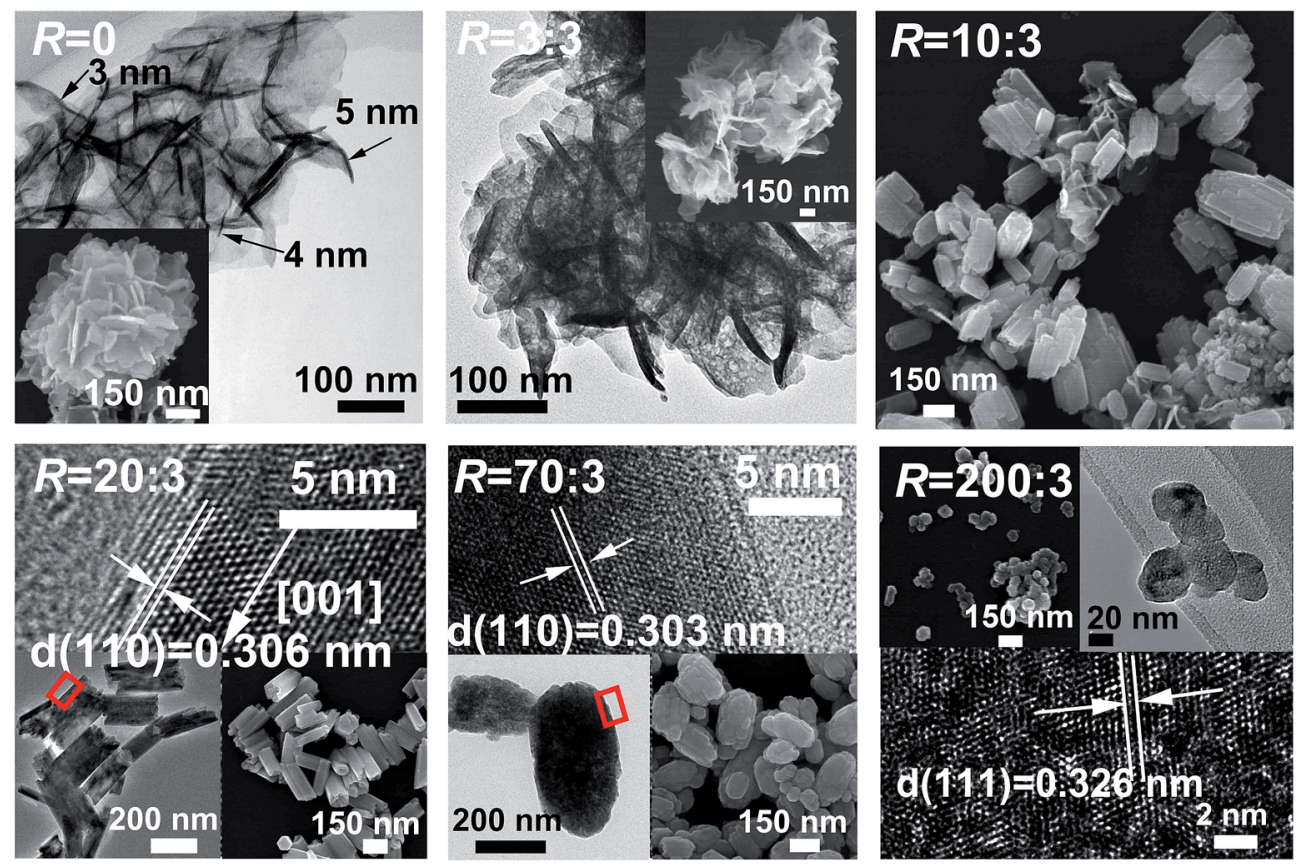

Fig. 4 FE-SEM and TEM analysis of the products obtained under the different F/RE molar ratios $(R)$ indicated in the figure. 


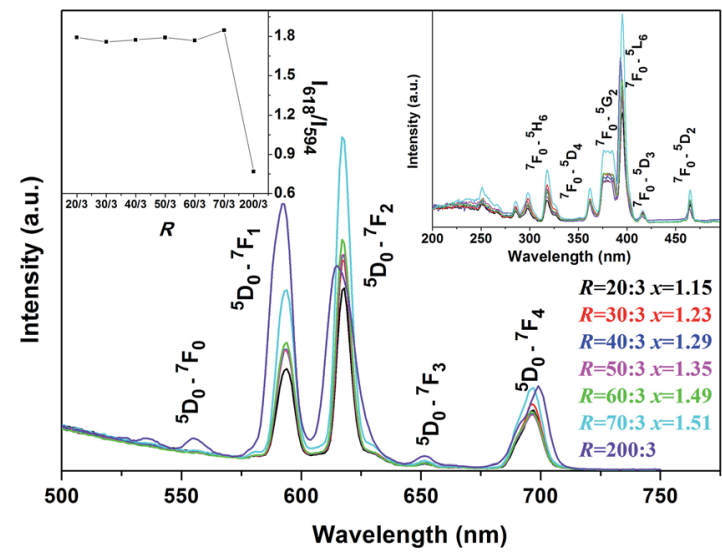

Fig. $5 \mathrm{PL}$ spectra of the $\mathrm{RE}(\mathrm{OH})_{3-x} \mathrm{~F}_{x}$ and $\mathrm{K}_{5} \mathrm{RE}_{9} \mathrm{~F}_{32}$ products obtained under $R=20: 3-70: 3$ and $200: 3$, respectively. The right- and lefthand insets are for excitation spectra and asymmetry factor of luminescence, respectively.

emission and excitation intensities tend to increase with increasing $R$, which could be due to the gradually lower $\mathrm{OH}^{-}$ content (higher $\mathrm{F}^{-}$content) in $\mathrm{RE}(\mathrm{OH})_{3-x} \mathrm{~F}_{x}$, since hydroxyls are known to substantially quench the luminescence of rare-earth activators. The asymmetry factor of luminescence $\left[I\left({ }^{5} D_{0} \rightarrow{ }^{7} F_{2}\right) /\right.$ $I\left({ }^{5} \mathrm{D}_{0} \rightarrow{ }^{7} \mathrm{~F}_{1}\right)$ intensity ratio] keeps almost constant at $\sim 1.8$ for all the hydroxyfluoride samples (Fig. 5, the left-hand inset), which further illustrates that the observed PLE/PL enhancement with increasing $\mathrm{F}$ incorporation is due to the decreased content of $\mathrm{OH}^{-}$rather than changed coordination environment (site symmetry) of $\mathrm{Eu}^{3+} . \mathrm{K}_{5} \mathrm{RE}_{9} \mathrm{~F}_{32}$ has the fluorite-type cubic structure, which can be deemed as a random replacement of the $\mathrm{Ca}^{2+}$ sites of $\mathrm{CaF}_{2}$ by $\mathrm{K}^{+}$and $\mathrm{RE}^{3+}$ ions, and is similar to that of the cubicstructured $\alpha-\mathrm{NaYF}_{4}$ (Fig. $\mathrm{S} 4 \dagger$ ). ${ }^{49,60}$ As the $\mathrm{Eu}^{3+}$ ions in $\mathrm{K}_{5} \mathrm{RE}_{9} \mathrm{~F}_{32}$ would occupy the centrosymmetric $O_{h}$ lattice sites, ${ }^{57,61}$ stronger ${ }^{5} \mathrm{D}_{0} \rightarrow{ }^{7} \mathrm{~F}_{1}$ emission ( $\sim 592 \mathrm{~nm}$, parity allowed magnetic dipole transition) over ${ }^{5} \mathrm{D}_{0} \rightarrow{ }^{7} \mathrm{~F}_{2}$ emission ( $\sim 617 \mathrm{~nm}$, parity forbidden electric dipole transition) is thus observed from the PL spectrum under $395 \mathrm{~nm}$ excitation, and is in compliance with the less than unit $(\sim 0.77)$ asymmetry factor of luminescence (Fig. 5, the left-hand inset). The PLE spectrum obtained by monitoring the ${ }^{5} \mathrm{D}_{0} \rightarrow{ }^{7} \mathrm{~F}_{1}$ emission (592 $\mathrm{nm}$ ) presents excitations essentially identical to those of the $\mathrm{RE}(\mathrm{OH})_{3-x} \mathrm{~F}_{x}$ hydroxyfluorides in band position, and the excitation intensity well conforms to the emission intensity.

\section{Phase/morphology evolution upon heating and characterization of the calcination products}

The thermal behaviour of $\mathrm{RE}(\mathrm{OH})_{3-x} \mathrm{~F}_{x}$ was analysed via TG using the composition $\mathrm{RE}(\mathrm{OH})_{1.49} \mathrm{~F}_{1.51}(R=70: 3)$ as an example (Fig. 6). Three distinct stages of decomposition were observed for the sample, with the initial weight loss of $\sim 2.5 \mathrm{wt} \%$ owing to the evaporation of adsorbed species (such as $\mathrm{H}_{2} \mathrm{O}$ molecules, up to $\sim 200{ }^{\circ} \mathrm{C}$ ) and the second loss of $\sim 9.32 \%$ $\left(\sim 200-450{ }^{\circ} \mathrm{C}\right)$ owing to the dehydroxylation of $\mathrm{RE}(\mathrm{OH})_{1.49} \mathrm{~F}_{1.51}$ to form oxyfluoride according to the equation of $\mathrm{RE}(\mathrm{OH})_{1.49} \mathrm{~F}_{1.51}$ $=\mathrm{REO}_{0.745} \mathrm{~F}_{1.51}+0.745 \mathrm{H}_{2} \mathrm{O}$. The theoretical weight loss

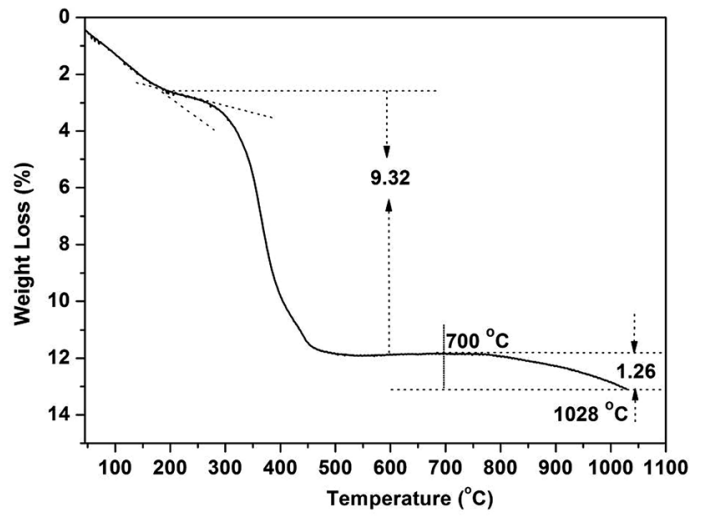

Fig. $6 \mathrm{TG}$ analysis of the $\left(\mathrm{Y}_{0.95} \mathrm{Eu}_{0.05}\right)(\mathrm{OH})_{1.49} \mathrm{~F}_{1.51}$ product in air $(R=$ $70: 3)$.

calculated from the above equation $(\sim 9.18 \mathrm{wt} \%)$ is indeed very close to the observed value of $\sim 9.32 \%$. The gradual weight loss occurring at temperatures above $\sim 700{ }^{\circ} \mathrm{C}$ (third stage) is due to oxidation of $\mathrm{REO}_{0.745} \mathrm{~F}_{1.51}$ to form the nominal composition of $\operatorname{REO}_{(0.745+y / 2)} \mathrm{F}_{1.51-y}$. Taking the $1.26 \%$ of weight loss at $1028{ }^{\circ} \mathrm{C}$ for example, the $y$ value was assayed to be $\sim 0.088$. That is, the product at $1028{ }^{\circ} \mathrm{C}$ would have the nominal composition of $\mathrm{REO}_{0.789} \mathrm{~F}_{1.422}$.

Fig. 7 exhibits XRD patterns of the products obtained by thermal decomposition of the as-prepared $\mathrm{RE}(\mathrm{OH})_{3-x} \mathrm{~F}_{x}$ $(x=1.15-1.51, R=20: 3-70: 3)$ in air at $450{ }^{\circ} \mathrm{C}$ for $2 \mathrm{~h}$. It is seen that the samples from the $\mathrm{RE}(\mathrm{OH})_{3-x} \mathrm{~F}_{x}$ of $x=1.29-1.51$ $(R=40: 3-70: 3$, Table 1$)$ can be indexed with the orthorhombic-structured $\mathrm{Y}_{5} \mathrm{O}_{4} \mathrm{~F}_{7}$ phase (JCPDS no. 80-1124) while that from the least-F containing $\mathrm{RE}(\mathrm{OH}){ }_{1.85} \mathrm{~F}_{1.15}(x=1.15$, $R=20: 3$ ) shows peak splitting (Fig. 7a) and are assignable to a mixture of hexagonal REOF (JCPDS no. 71-2100) and $\mathrm{RE}_{5} \mathrm{O}_{4} \mathrm{~F}_{7}$ phases. The calcination product of $\mathrm{RE}(\mathrm{OH})_{1.77} \mathrm{~F}_{1.23}(R=30: 3)$ should also contain a small amount of REOF, as perceived from the existence of a right-hand tail in the amplified diffraction peak in Fig. 7b. Analysis of the phase constituent via Rietveld fitting of the XRD patterns (Fig. $\mathrm{S} 5 \dagger$ ) indeed found that the products calcined from $\mathrm{RE}(\mathrm{OH})_{1.85} \mathrm{~F}_{1.15}$ and $\mathrm{RE}(\mathrm{OH})_{1.77} \mathrm{~F}_{1.23}$ contain $\sim 44.0( \pm 0.6)$ and $11.8( \pm 0.5) \%$ of the REOF phase, respectively. With the three decomposition products of $R=50$ 70 for example, we performed elemental analysis and the results are presented in Table 2 . It is seen that the actual $\mathrm{F}$ content gradually increases towards a larger $R$, and the three $\mathrm{RE}_{5} \mathrm{O}_{4} \mathrm{~F}_{7}$ phases have the deduced compositions of $\mathrm{REO}_{0.81} \mathrm{~F}_{1.38}$ $\left(\mathrm{RE}_{5} \mathrm{O}_{4.05} \mathrm{~F}_{6.90}, R=50: 3\right), \mathrm{REO}_{0.78} \mathrm{~F}_{1.44}\left(\mathrm{RE}_{5} \mathrm{O}_{3.90} \mathrm{~F}_{7.20}, R=60: 3\right)$, and $\mathrm{REO}_{0.755} \mathrm{~F}_{1.49}\left(\mathrm{RE}_{5} \mathrm{O}_{3.775} \mathrm{~F}_{7.45}, R=70: 3\right)$ if the trace amount of $\mathrm{KF}$ contaminant is ignored in each case. The slight (151) peak shifting observed in Fig. 7a could be due to the different $\mathrm{F}$ content of the products. In addition, the as-said $\mathrm{RE}_{5} \mathrm{O}_{4} \mathrm{~F}_{7}$ products were assayed from their (151) diffractions with the Scherrer formula to have the average crystallite sizes of $\sim 15 \pm 2 \mathrm{~nm}$, not significantly affected by the $R$ value or the actual content of $\mathrm{F}$.

SEM and TEM analysis (Fig. 8) showed that the products well-retained the overall morphologies and particle sizes of their respective hydroxyfluoride parents. The particles are 


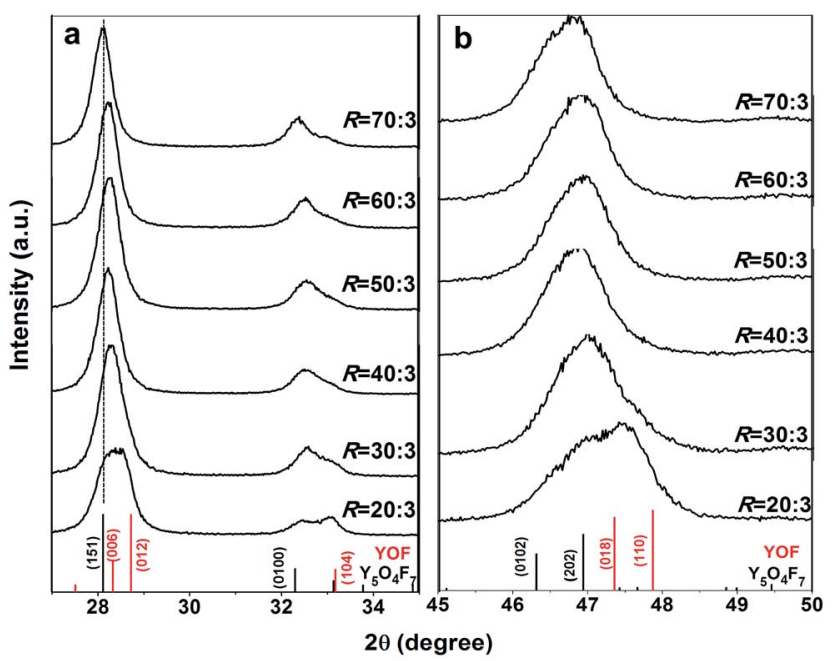

Fig. 7 Powder XRD patterns of the products obtained by calcining $\mathrm{RE}(\mathrm{OH})_{3-x} \mathrm{~F}_{x}(x=1.15-1.51, R=20: 3-70: 3)$ in air at $450{ }^{\circ} \mathrm{C}$ for $2 \mathrm{~h}$. (a) and (b) are enlarged views of the $2 \theta=27-35^{\circ}$ and $45-50^{\circ}$ regions, respectively. The standard diffractions of orthorhombic $\mathrm{Y}_{5} \mathrm{O}_{4} \mathrm{~F}_{7}$ (JCPDS no. 80-1124) and hexagonal YOF (JCPDS no. 71-2100) are presented as bars for comparison.

Table 2 Elemental analysis of the $\left(\mathrm{Y}_{0.95} \mathrm{Eu}_{0.05}\right) \mathrm{O}_{(3-x) / 2} \mathrm{~F}_{x}$ oxyfluorides calcined from $\mathrm{RE}(\mathrm{OH})_{3-x} \mathrm{~F}_{x}(R=50: 3-70: 3)$ in air at $450{ }^{\circ} \mathrm{C}$ for $2 \mathrm{~h}$

\begin{tabular}{|c|c|c|c|c|c|c|c|c|c|}
\hline \multirow{3}{*}{$\frac{R}{50}$} & \multicolumn{4}{|c|}{ Analysed content (wt\%) } & \multicolumn{4}{|c|}{ Derived molar ratio } & \multirow[b]{2}{*}{$x$} \\
\hline & $\mathrm{Y}$ & $\mathrm{Eu}$ & $\mathrm{F}$ & $\mathrm{K}$ & $n \mathrm{Y}:$ & $\mathrm{u}: n \mathrm{~F}$ & $n \mathrm{~K}$ & & \\
\hline & 62.8 & 5.6 & 19.5 & 0.64 & 0.95 & 0.05 & 1.38 & 0.02 & 1.38 \\
\hline 60 & 62.3 & 5.5 & 20.2 & 0.82 & 0.95 & 0.05 & 1.44 & 0.03 & 1.44 \\
\hline 70 & 61.9 & 5.5 & 20.8 & 0.97 & 0.95 & 0.05 & 1.49 & 0.03 & 1.49 \\
\hline
\end{tabular}

apparently polycrystalline in view of the crystallite size in each case. HR-TEM analysis of the $\mathrm{REO}_{0.755} \mathrm{~F}_{1.49}$ powder $(R=70: 3)$ found interplanar spacings of $\sim 0.317 \mathrm{~nm}$, which may correspond to the (151) crystal plane. The result also indicates that the oxyfluoride powder has good crystallinity despite the low calcination temperature.

Fig. 9 shows PLE and PL spectra of the $\mathrm{REO}_{(3-x) / 2} \mathrm{~F}_{x}$ products (the said $\mathrm{RE}_{5} \mathrm{O}_{4} \mathrm{~F}_{7}$ phases, $x=1.38-1.49 ; R=40: 3-70: 3$ ). The strong excitation bands of $\mathrm{O}^{2-}-\mathrm{Eu}^{3+}$ CTB are located with maxima at $\sim 253 \mathrm{~nm}$, while the weaker peaks in the longer wavelength region $(\sim 300-500 \mathrm{~nm})$ can be assigned to the intra$4 f^{6}$ transitions of $\mathrm{Eu}^{3+}$. Owing to the much greater energy needed to remove an electron from $\mathrm{F}^{-}$than from $\mathrm{O}^{2-}, \mathrm{F}^{-}-\mathrm{Eu}^{3+}$ CTB, which generally occurs below $200 \mathrm{~nm}$ in the excitation spectrum, is not present in the PLE spectra of this work. Considering that the electronegativity of F (3.98) is higher than that of O (3.44), blue-shifted CTB was initially expected for the oxyfluoride of a higher F content. The almost constant СТВ centre actually observed in this work may suggest that the $\mathrm{F}^{-}$ anions have not been as well coordinated to $\mathrm{RE}^{3+}$ as $\mathrm{O}^{2-}$ in the molecules or the $\mathrm{F}$ content has not been sufficiently different to reveal the effects of ligand electronegativity. $\mathrm{RE}_{5} \mathrm{O}_{4} \mathrm{~F}_{7}$ provides the approximate $C_{4 v}$ site symmetry for the $\mathrm{Eu}^{3+}$ activator, ${ }^{54}$ and thus PL spectra dominated by the ${ }^{5} \mathrm{D}_{0} \rightarrow{ }^{7} \mathrm{~F}_{2}$ electric dipole transition at $\sim 614 \mathrm{~nm}$ were yielded. The enhanced excitation and emission intensity at a higher $R$ or F content could probably be due to improved crystallinity of the oxyfluoride by the flux effects of $\mathrm{F}^{-}$anions. With the ${ }^{5} \mathrm{D}_{0} \rightarrow{ }^{7} \mathrm{~F}_{2}$ emission $(614 \mathrm{~nm})$ for example, the oxyfluorides have the increasing intensity ratio of $1: 1.33: 1.50: 1.79$ with the $R$ increasing from $40: 3$ to $70: 3$ (Fig. 9b).

Structure stability of the oxyfluoride was studied with the most $\mathrm{F}$ rich hydroxyfluoride of $\mathrm{RE}(\mathrm{OH})_{1.49} \mathrm{~F}_{1.51}(R=70: 3)$ for sample, and the $450{ }^{\circ} \mathrm{C}$ product of which is $\mathrm{REO}_{0.755} \mathrm{~F}_{1.49}$ as aforementioned. Fig. 10 shows XRD patterns of the products calcined in air at various temperatures for $2 \mathrm{~h}$. It is seen that those obtained in the range of $450-700{ }^{\circ} \mathrm{C}$ can be assigned to the orthorhombic $\mathrm{RE}_{5} \mathrm{O}_{4} \mathrm{~F}_{7}$ phase. Elemental analysis of the $700{ }^{\circ} \mathrm{C}$ product found the $n \mathrm{Y}: n \mathrm{Eu}: n \mathrm{~F}: n \mathrm{~K}$ molar ratio of $0.95: 0.05: 1.40: 0.03$, and thus the chemical formula was derived to be $\left(\mathrm{Y}_{0.95} \mathrm{Eu}_{0.05}\right) \mathrm{O}_{0.80} \mathrm{~F}_{1.40}$. The sample apparently has less $\mathrm{F}$ than the $450{ }^{\circ} \mathrm{C}$ product of $\left(\mathrm{Y}_{0.95} \mathrm{Eu}_{0.05}\right) \mathrm{O}_{0.755} \mathrm{~F}_{1.49}$, indicating that slight $\mathrm{F}$ loss via oxidation has taken place, as also suggested by TG analysis (Fig. 6). Calcining at $900{ }^{\circ} \mathrm{C}$ led to the formation of hexagonal REOF, owing to the $\mathrm{F}$ loss via oxidation of $\mathrm{RE}_{5} \mathrm{O}_{4} \mathrm{~F}_{7}$. Partial oxidation of REOF took place at $1100{ }^{\circ} \mathrm{C}$, and thus a phase mixture of hexagonal REOF and trace cubic $\mathrm{RE}_{2} \mathrm{O}_{3}$ (JCPDS no. 43-1036) was resulted.

Fig. 11 compares excitation and emission properties of the oxyfluorides obtained by calcining $\operatorname{RE}(\mathrm{OH})_{1.49} \mathrm{~F}_{1.51}(R=70: 3)$ in air at the three temperatures of 450,600 , and $700{ }^{\circ} \mathrm{C}$. The PLE spectra (Fig. 11a) show the $\mathrm{O}^{2-}-\mathrm{Eu}^{3+}$ charge transfer band (CTB) and the intra- $4 f^{6}$ transitions of $\mathrm{Eu}^{3+}$ as indicated in the figure. The PL spectra obtained under $255 \mathrm{~nm}$ excitation (Fig. 11b) show emission transitions from the ${ }^{5} \mathrm{D}_{0}$ excited state to the ${ }^{7} \mathrm{~F}_{J}(J=0-4)$ ground states of $\mathrm{Eu}^{3+}$ as marked in the figure, with the dominant red emission at $\sim 612 \mathrm{~nm}$ arising from the ${ }^{5} \mathrm{D}_{0} \rightarrow{ }^{7} \mathrm{~F}_{2}$ forced electric dipole transition. The intensity of PL/PLE bands steadily increases with rising temperature of calcination owing to improved crystallinity of the products. The $612 \mathrm{~nm}$ emission, for example, has the intensity ratio of $\sim 1: 1.51: 2.44$ for the oxyfluorides calcined at 450,600 , and $700^{\circ} \mathrm{C}$. Increasing temperature of calcination led to slight shift of the CTB centre from $\sim 253$ to $259 \mathrm{~nm}$, which could be due to the gradually higher oxygen content (less F) of the product and the smaller electronegativity of oxygen than fluorine. It was also noticed that the intra- $4 f^{6}$ transitions gradually gained intensity over СТВ with increasing temperature of calcination, as seen from Fig. 11a. That is, CTB dominates the excitation spectrum for the $450{ }^{\circ} \mathrm{C}$ product while the ${ }^{7} \mathrm{~F}_{0} \rightarrow{ }^{5} \mathrm{~L}_{6}$ intra- $4 f^{6}$ transition is the strongest for the $700^{\circ} \mathrm{C}$ one. The phenomenon may again suggest that $\mathrm{O}^{2-}$ is better coordinated to $\mathrm{RE}^{3+}$ than $\mathrm{F}^{-}$in the $450{ }^{\circ} \mathrm{C}$ product, and as a result the PLE spectrum of this sample is similar to that widely observed for the $\mathrm{Y}_{2} \mathrm{O}_{3}$ :Eu red phosphor. Increasing temperature of calcination promotes crystallization and at the same time better coordination of $\mathrm{F}^{-}$to $\mathrm{RE}^{3+}$. As a result, CTB shows slower intensity increment than the intra- $4 f^{6}$ transitions since a significant mixing in of $\mathrm{F}$ in the $(\mathrm{O}, \mathrm{F})-\mathrm{RE}$ bond would reduce the efficiency of charge transfer by the higher 

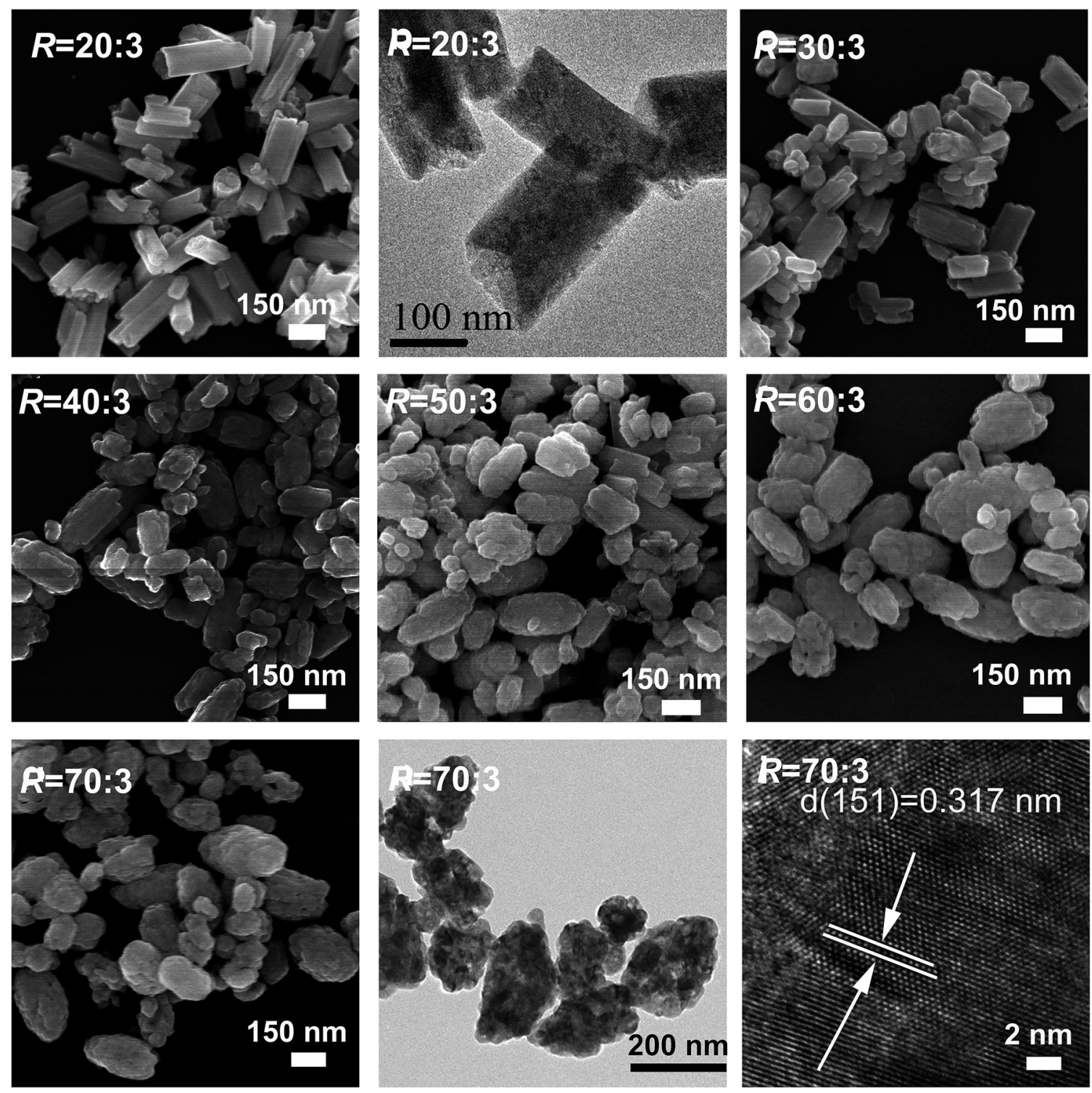

Fig. 8 FE-SEM and TEM analysis of the products calcined from $\mathrm{RE}(\mathrm{OH})_{3-x} \mathrm{~F}_{x}(x=1.15-1.51, R=20: 3-70: 3)$ in air at $450{ }^{\circ} \mathrm{C}$ for $2 \mathrm{~h}$.
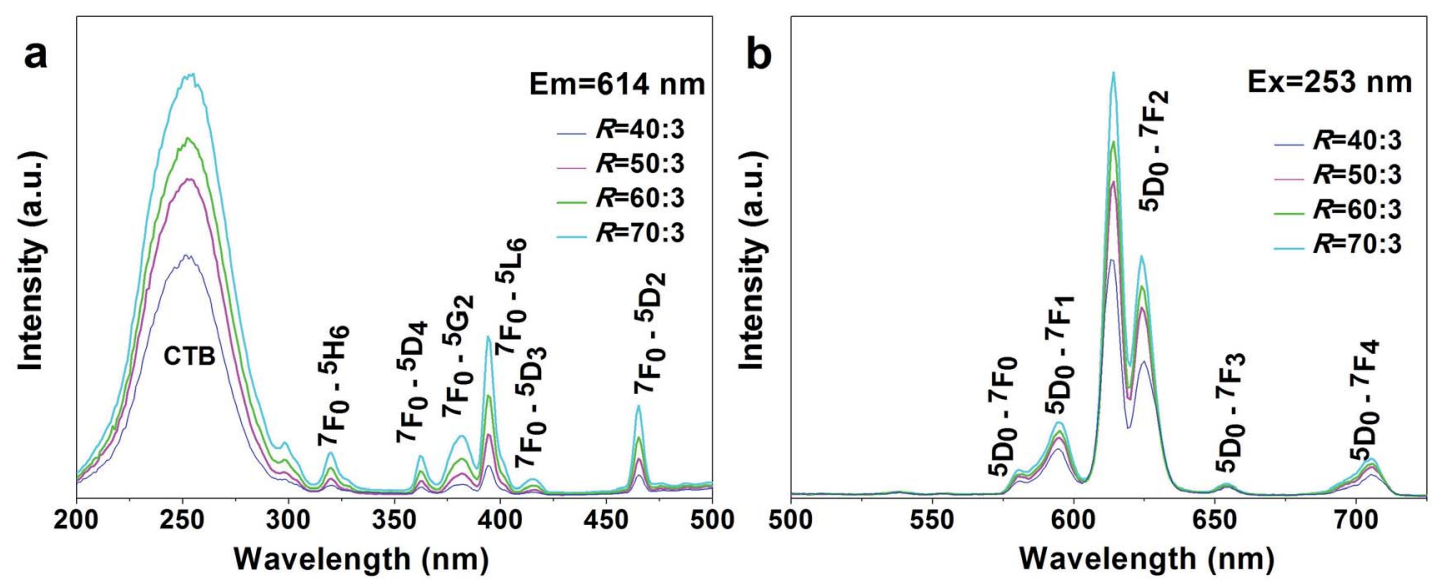

Fig. $9 \mathrm{PLE}(\mathrm{a})$ and $\mathrm{PL}(\mathrm{b})$ spectra of the $\mathrm{REO}_{(3-x) / 2} \mathrm{~F}_{x}$ products $(x=1.38-1.49)$ calcined from $\mathrm{RE}(\mathrm{OH})_{3-x} \mathrm{~F}_{x}(R=40: 3-70: 3)$ in air at $450{ }^{\circ} \mathrm{C}$ for $2 \mathrm{~h}$. The excitation and emission wavelengths used for the measurements are indicated in the figure. 


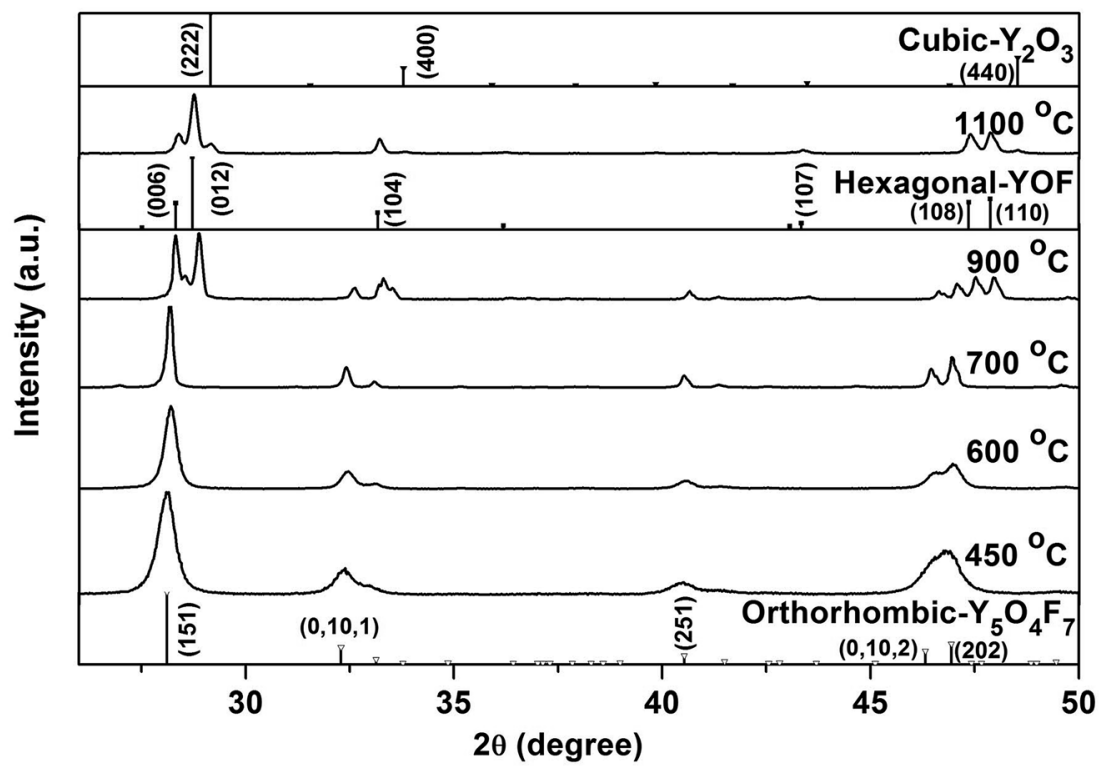

Fig. 10 Powder XRD patterns of the products calcined from $\mathrm{Y}(\mathrm{OH})_{1.49} \mathrm{~F}_{1.51}(R=70: 3)$ at the various temperatures indicated in the figure.

a

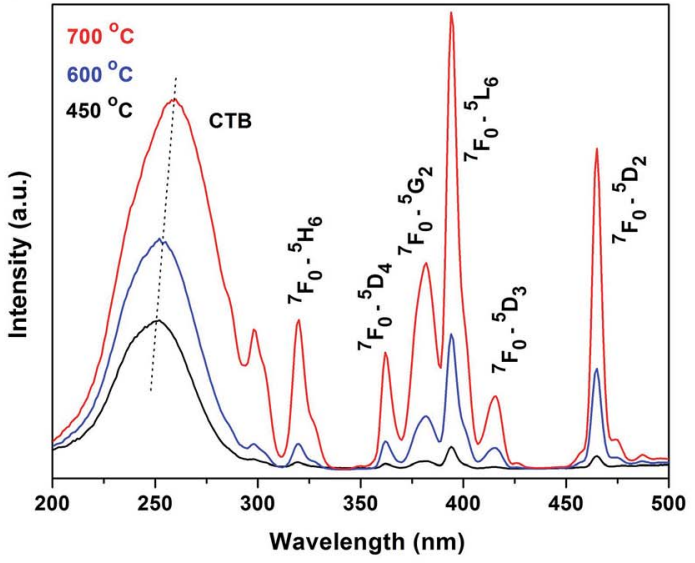

b

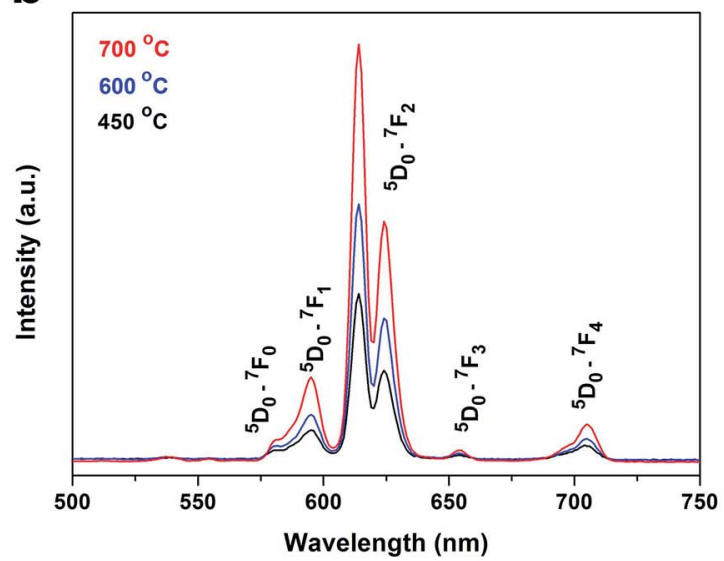

Fig. 11 PLE ((a) $\left.\lambda_{\text {em }}=614 \mathrm{~nm}\right)$ and PL ((b) $\left.\lambda_{\text {ex }}=255 \mathrm{~nm}\right)$ spectra of the oxyfluorides calcined from $\mathrm{Y}(\mathrm{OH})_{1.49} \mathrm{~F}_{1.51}(R=70: 3)$ in air the temperatures indicated in the figure.

electronegativity of F. Fluorescence decay curves of the three oxyfluoride phosphors are shown in Fig. S6, $\dagger$ where it was found that the decay kinetics can all be well fitted with the single exponential of $I=A \exp \left(-t / \tau_{\mathrm{R}}\right)+B$, where $\tau_{\mathrm{R}}, t$ and $I$ denote the fluorescence lifetime, delay time and relative intensity, respectively, and $A$ and $B$ are constants. The phosphors calcined at 450, 600 and $700{ }^{\circ} \mathrm{C}$ were analysed to have the increasing lifetime values of $1.39( \pm 0.01), 2.34( \pm 0.01)$ and $2.48( \pm 0.01) \mathrm{ms}$ and the gradually higher internal/external quantum yields (in percentage) of 33.2/15.9, 45.0/24.2 and 51.0/31.6, respectively. The successively longer fluorescence lifetime and higher quantum yield observed for a higher calcination temperature are primarily owing to the elimination of luminescence quenching defects and improved crystallinity, through crystallite growth, of the phosphor powder.

\section{Conclusions}

$\mathrm{RE}(\mathrm{OH})_{3-x} \mathrm{~F}_{x}$ hydroxyfluoride $(x=1.15-1.51)$ and $\mathrm{K}_{5} \mathrm{RE}_{9} \mathrm{~F}_{32}$ crystals have been successfully converted from the nanosheets ( $\sim 4 \mathrm{~nm}$ thick) of $\mathrm{RE}_{2}(\mathrm{OH})_{5} \mathrm{NO}_{3} \cdot n \mathrm{H}_{2} \mathrm{O}$ layered hydroxyl nitrate ( $\mathrm{LREH}-\mathrm{NO}_{3}{ }^{-}, \mathrm{RE}=\mathrm{Y}_{0.95} \mathrm{Eu}_{0.05}$ ) via reacting with $\mathrm{KF}$ solution at the low temperature of $\sim 90{ }^{\circ} \mathrm{C}$. Calcining $\mathrm{RE}(\mathrm{OH})_{3-x} \mathrm{~F}_{x}$ of the relatively high $\mathrm{F}$ content of $x=1.29-1.51$ at $4500^{\circ} \mathrm{C}$ in air has also produced $\mathrm{REO}_{(3-x) / 2} \mathrm{~F}_{x}$ oxyfluorides that are analogous to the orthorhombic structured $\mathrm{Y}_{5} \mathrm{O}_{4} \mathrm{~F}_{7}$ phase. It was shown that the actual $\mathrm{F}$ content of the product is dependent on the F/RE molar ratio used for phase conversion and the temperature of subsequent calcination. Oxidation of $\mathrm{REO}_{(3-x) / 2} \mathrm{~F}_{x}$ to form REOF and even $\mathrm{RE}_{2} \mathrm{O}_{3}$ was observed at temperatures above $\sim 700{ }^{\circ} \mathrm{C}$. The resultant hydroxyfluorides, oxyfluorides and complex fluoride 
were shown to exhibit photoluminescence dependent on the crystal structure of the host lattice, F content, and temperature of calcination.

\section{Conflicts of interest}

There are no conflicts to declare.

\section{Acknowledgements}

This work was supported in part by the National Natural Science Foundation of China (Grants No. 51672039, 51702020, and U1302272) and the Fundamental Research Funds for the Central Universities (Grants N160204008). Jing Li was funded by the China Scholarship Council (Grant No. 201206080059) during this work.

\section{References}

1 J. L. Zhuang, L. F. Liang, H. H. Y. Sung, X. F. Yang, M. M. Wu, I. D. Williams, S. H. Feng and Q. Su, Inorg. Chem., 2007, 46, 5404-5410.

2 M. Y. Ding, C. H. Lu, L. H. Cao, J. B. Song, Y. Ni and Z. Z. Xu, J. Mater. Sci., 2013, 48, 4989-4998.

3 J. X. Fu, X. H. Fu, C. M. Wang, X. F. Yang, J. L. Zhuang, G. G. Zhang, B. Y. Lai, M. M. Wu and J. Wang, Eur. J. Inorg. Chem., 2013, 1269-1274.

4 B.-Q. Liu, K. Guo, J. Wang, Z.-J. Zhang, Y. Tao, Y. Huang and J.-T. Zhao, Mater. Lett., 2013, 100, 245-247.

5 J. L. Zhuang, X. F. Yang, J. X. Fu, C. L. Liang, M. M. Wu, J. Wang and Q. Su, Cryst. Growth Des., 2013, 13, 2292-2297. 6 X. H. He and B. Yan, CrystEngComm, 2015, 17, 621-627.

7 D.-Q. Zhang, T.-Y. Sun, X.-F. Yu, Y. Jia, M. Chen, J.-H. Wang, H. Huang and P. K. Chu, Mater. Res. Bull., 2014, 52, 122-127. 8 H. Wagata, T. Wakabayashi, S. Suzuki, M. Tanaka, H. Nishikiori, S. Oishi and K. Teshima, Cryst. Growth Des., 2013, 13, 1187-1192.

9 Y. Zhang, D. L. Geng, X. J. Kang, M. M. Shang, Y. Wu, X. Li, H. Z. Lian, Z. Y. Cheng and J. Lin, Inorg. Chem., 2013, 52, 12986-12994.

10 L. S. Liu, H. H. Chen, B. Q. Liu, H. Zhang, B. Tang, X. J. Feng, Z. J. Sun and J. T. Zhao, J. Rare Earths, 2014, 32, 686-690.

11 L. Tao, W. Xu, Y. S. Zhu, L. Xu, H. C. Zhu, Y. X. Liu, S. Xu, P. W. Zhou and H. W. Song, J. Mater. Chem. C, 2014, 2, 4186-4195.

12 M. Y. Ding, D. Q. Chen, Z. Y. Wan, Y. Zhou, J. S. Zhong, J. H. Xi and Z. G. Ji, J. Mater. Sci., 2015, 50, 6779-6785.

13 E. Martinez-Castro, J. Garcia-Sevillano, F. Cusso and M. Ocana, J. Alloys Compd., 2015, 619, 44-51.

14 B. Q. Shao, Q. Zhao, W. Z. Lv, M. M. Jiao, W. Lue and H. P. You, Adv. Opt. Mater., 2015, 3, 583-592.

15 H.-X. Mai, Y.-W. Zhang, R. Si, Z.-G. Yan, L.-D. Sun, L.-P. You and C.-H. Yan, J. Am. Chem. Soc., 2006, 128, 6426-6436.

16 H. Nishizawa, K. Okumoto and T. Mitsushio, J. Solid State Chem., 1991, 92, 370-379.

17 A. Marbeuf, G. Demazeau, S. Turrell and P. Hagenmuller, J. Solid State Chem., 1971, 3, 637-641.
18 L. Tian, W. T. Jiang, Q. L. Sun and J. Liu, J. Rare Earths, 2012, 30, 378-382.

19 Y. Zhang, X. J. Li, D. L. Geng, M. M. Shang, H. Z. Lian, Z. Y. Cheng and J. Lin, CrystEngComm, 2014, 16, 2196-2204.

20 M. Ma, C. F. Xu, L. W. Yang, G. Z. Ren, J. G. Lin and Q. B. Yang, Phys. B, 2011, 406, 3256-3260.

21 R. Q. Li, Y. Liu, N. N. Zhang, L. L. Li, L. Liu, Y. M. Liang and S. C. Gan, J. Mater. Chem. C, 2015, 3, 3928-3934.

22 B. Q. Liu, L. S. Liu, K. Guo, J. Wang, L. L. Zhu, H. Zhang, W. Wen, T. Y. Yang and J. T. Zhao, J. Rare Earths, 2013, 31, 745-749.

23 L. N. Guo, Y. H. Wang, L. L. Han, Q. P. Qiang, W. Zeng, Z. H. Zou, B. Wang and X. X. Guo, J. Mater. Chem. C, 2013, 1, 7952-7962.

24 G. Jia, H. P. You, Y. H. Song, J. J. Jia, Y. H. Zheng, L. H. Zhang, K. Liu and H. J. Zhang, Inorg. Chem., 2009, 48, 10193-10201. 25 Z. H. Xu, C. X. Li, P. P. Yang, C. M. Zhang, S. S. Huang and J. Lin, Cryst. Growth Des., 2009, 9, 4752-4758.

26 F. Zhang and D. Y. Zhao, ACS Nano, 2009, 3, 159-164.

27 J. Xu, S. L. Gai, P. A. Ma, Y. L. Dai, G. X. Yang, F. He and P. P. Yang, J. Mater. Chem. B, 2014, 2, 1791-1801.

28 Y. H. Han, S. L. Gai, P. A. Ma, L. Z. Wang, M. L. Zhang, S. H. Huang and P. P. Yang, Inorg. Chem., 2013, 52, 91849191.

29 F. X. Geng, R. Z. Ma and T. Sasaki, Acc. Chem. Res., 2010, 43, 1177-1185.

30 X. L. Wu, J.-G. Li, J. K. Li, Q. Zhu, X. D. Li, X. D. Sun and Y. Sakka, Sci. Technol. Adv. Mater., 2013, 14, 015006.

31 X. L. Wu, J.-G. Li, D.-H. Ping, J. K. Li, Q. Zhu, X. D. Li, X. D. Sun and Y. Sakka, J. Alloys Compd., 2013, 559, 188-195. 32 Q. Zhu, J.-G. Li, R. Z. Ma, T. Sasaki, X. J. Yang, X. D. Li, X. D. Sun and Y. Sakka, J. Solid State Chem., 2012, 192, 229-237.

33 Q. Zhu, J.-G. Li, C. Y. Zhi, X. D. Li, X. D. Sun, Y. Sakka, D. Golberg and Y. Bando, Chem. Mater., 2010, 22, 4204-4213. 34 Q. Zhu, J.-G. Li, X. D. Li, X. D. Sun, Y. Qi, M. Y. Zhu and Y. Sakka, Sci. Technol. Adv. Mater., 2014, 15, 014203.

35 Q. Zhu, J. G. Li, C. Zhi, R. Ma, T. Sasaki, J. X. Xu, C. H. Liu, X. D. Li, X. D. Sun and Y. Sakka, J. Mater. Chem., 2011, 21, 6903-6908.

36 L. F. Hu, R. Z. Ma, T. C. Ozawa and T. Sasaki, Chem.-Asian J., 2010, 5, 248-251.

37 X. L. Wu, J.-G. Li, Q. Zhu, W. G. Liu, J. Li, X. D. Li, X. D. Sun and Y. Sakka, J. Mater. Chem. C, 2015, 3, 3428-3437.

38 F. X. Geng, Y. Matsushita, R. Z. Ma, H. Xin, M. Tanaka, N. Iyi and T. Sasaki, Inorg. Chem., 2009, 48, 6724-6730.

39 K.-H. Lee and S.-H. Byeon, Eur. J. Inorg. Chem., 2009, 929936.

40 K.-H. Lee and S.-H. Byeon, Eur. J. Inorg. Chem., 2009, 47274732.

41 L. J. McIntyre, L. K. Jackson and A. M. Fogg, Chem. Mater., 2008, 20, 335-340.

42 Y. S. Zhao, J.-G. Li, M. X. Guo and X. J. Yang, J. Mater. Chem. C, 2013, 1, 3584-3592.

43 X. L. Wu, J.-G. Li, Q. Zhu, J. K. Li, R. Z. Ma, T. Sasaki, X. D. Li, X. D. Sun and Y. Sakka, Dalton Trans., 2012, 41, 1854-1861. 
44 S. A. Hindocha, L. J. McIntyre and A. M. Fogg, J. Solid State Chem., 2009, 182, 1070-1074.

45 L. J. McIntyre, T. J. Prior and A. M. Fogg, Chem. Mater., 2010, 22, 2635-2645.

46 J. Li, J.-G. Li, Q. Zhu and X. Sun, Mater. Des., 2016, 112, 207216.

47 R. D. Shannon, Acta Crystallogr., Sect. A: Cryst. Phys., Diffr., Theor. Gen. Crystallogr., 1976, 32, 751-767.

48 J. Wen, L. Ning, C.-K. Duan, Y. Chen, Y. Zhang and M. Yin, J. Phys. Chem. C, 2012, 116, 20513-20521.

49 S. L. Gai, G. X. Yang, X. B. Li, C. X. Li, Y. L. Dai, F. He and P. P. Yang, Dalton Trans., 2012, 41, 11716-11724.

50 W. L. Li, Q. Y. Gu, F. F. Su, Y. H. Sun, G. B. Sun, S. L. Ma and X. J. Yang, Inorg. Chem., 2013, 52, 14010-14017.

51 Q. Zhu, J.-G. Li, X. D. Li, Y. Qi and X. D. Sun, $R S C A d v ., 2015$, 5, 64588-64595.

52 K. Nakamoto, Infrared and Raman Spectra of Inorganic and Coordination Compounds, John Wiley \& Sons, Inc., New Jersey, 6th edn, 2009.
53 Q. G. Zeng, Z. J. Ding, Z. M. Zhang and Y. Q. Sheng, J. Phys. Chem. C, 2010, 114, 4895-4900.

54 S. Fujihara, S. Koji, Y. Kadota and T. Kimura, J. Am. Ceram. Soc., 2004, 87, 1659-1662.

55 D. Zakaria, R. Mahiou, D. Avignant and M. Zahir, J. Alloys Compd., 1997, 257, 65-68.

56 Z.-G. Wei, L.-D. Sun, X.-C. Jiang, C.-S. Liao and C.-H. Yan, Chem. Mater., 2003, 15, 3011-3017.

57 F. Wang, X. P. Fan, D. B. Pi and M. Q. Wang, Solid State Commun., 2005, 133, 775-779.

58 B. R. Judd, Phys. Rev., 1962, 127, 750-761.

59 Z. H. Xu, C. X. Li, P. P. Yang, C. M. Zhang, S. Huang and J. Lin, Cryst. Growth Des., 2009, 9, 4752-4758.

60 P. Ghosh and A. Patra, J. Phys. Chem. C, 2008, 112, 32233231.

61 G. K. Liu, Chem. Soc. Rev., 2015, 44, 1635-1652. 